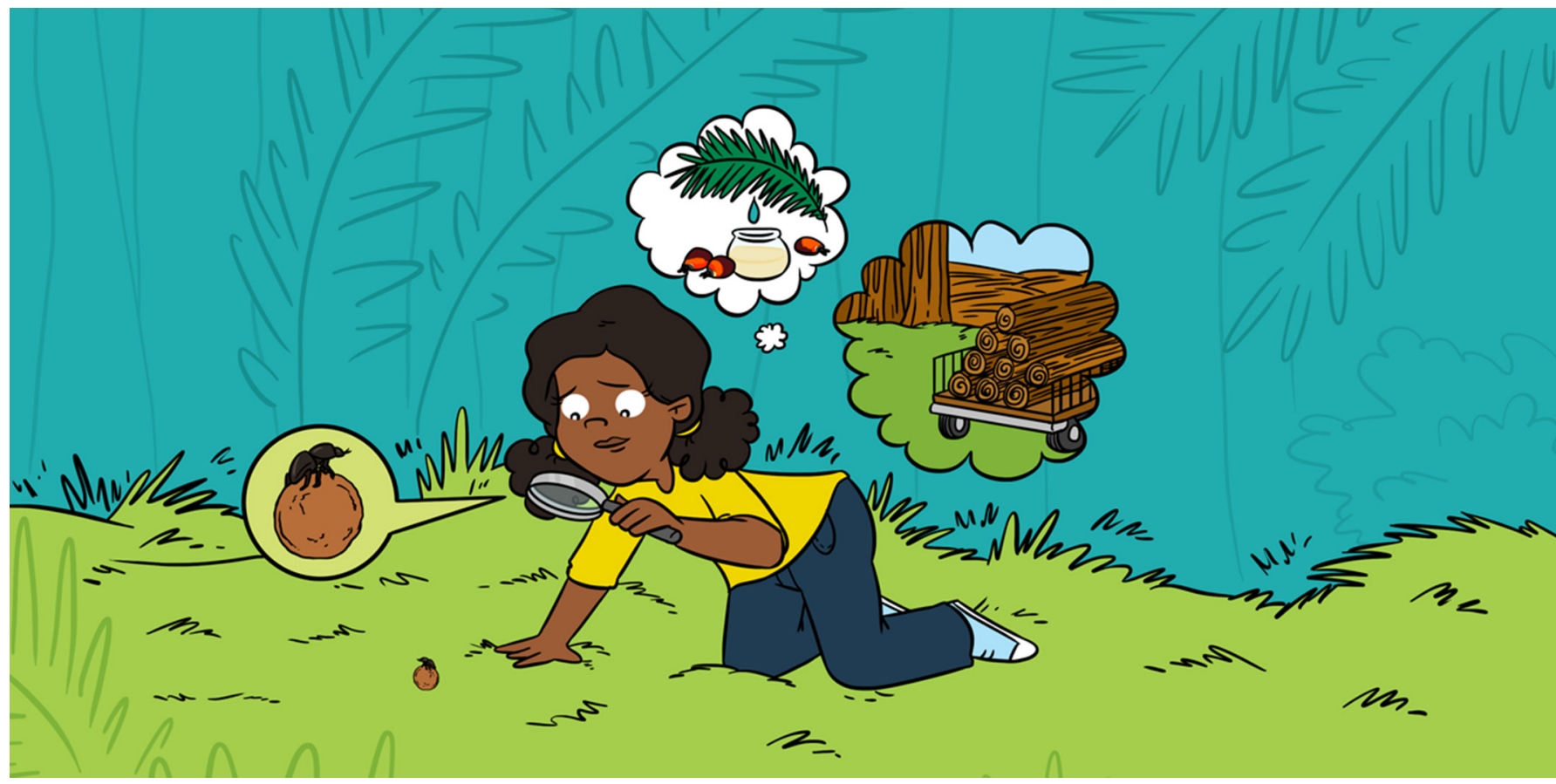

\title{
DUNG BEETLES HELP KEEP ECOSYSTEMS HEALTHY
}

\section{Paul Manning ${ }^{1 *}$, Xin Rui Ong ${ }^{2}$ and Eleanor M. Slade ${ }^{2}$}

${ }^{1}$ Faculty of Agriculture, Dalhousie University, Truro, NS, Canada

${ }^{2}$ Asian School of the Environment, Nanyang Technological University, Singapore, Singapore

YOUNG REVIEWERS:

FDR-HB_ PERU IGEM

TEAM

AGES: $14-17$
Dung beetles are a group of insects that primarily use the dung (poop) of mammals for feeding and nesting. These beetles are important for the breakdown and recycling of dung into the soil, enabling the nutrients in the dung to cycle through the ecosystem. Dung beetles provide many benefits for the health and functioning of both natural and human-modified ecosystems, such as dispersing seeds, reducing livestock parasites, and promoting plant growth. In this article, we will explore the basic life history of dung beetles. We then dig a little deeper into the importance of dung beetles within tropical forests and agricultural ecosystems.

\section{DUNG BEETLE BASICS}

Many readers will be familiar with dung beetles from nature documentaries. Once you have seen a beetle skillfully roll away a ball of dung (animal poop), the sight is hard to forget. Readers might be surprised to learn that dung beetles are found across most of the world (Figures 1A-D), on all continents except Antarctica! This group 
Figure 1

Examples of dung beetles in temperate and tropical environments. (A) The dweller Aphodius rufipes is a nocturnally active species found in high abundance in agricultural ecosystems. It is an important food source for bats. (B) The tunneller Onthophagus coenobita occurs in agricultural ecosystems, and often carries tiny mites that use dung beetles to transport them between dung pats. (C) Male Proagoderus watanabei, a tunneling species found in Sabah, Malaysia, feeding on dung. (D)

Paragymnopleurus maurus, a rolling species found in Sabah, Malaysia, pushes a dung ball to safety using its back legs.

\section{ORGANIC MATTER}

Compounds that have come from the remains of dead organisms, such as plants, fungi, and animals.

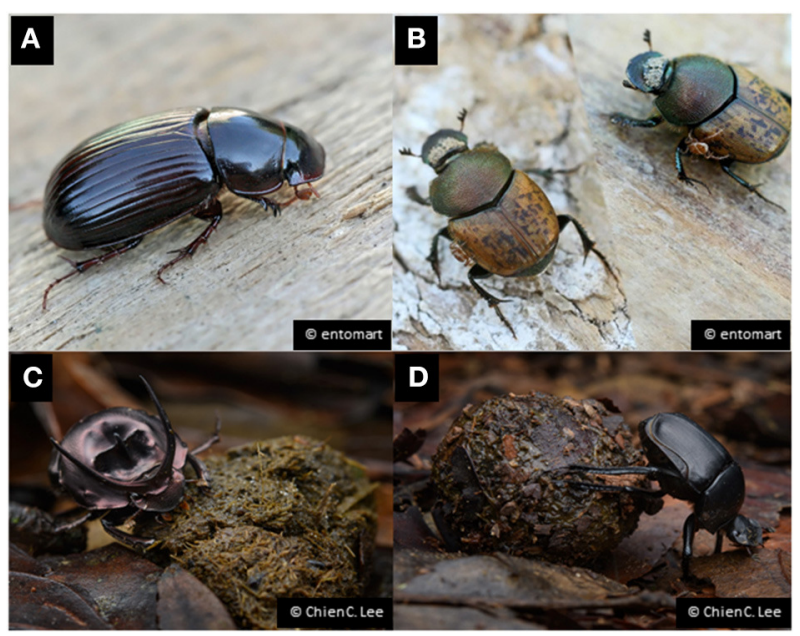

Figure 1

of beetles is named for its habit of using the dung of mammals for food and nesting. Although, some species of dung beetles opt for decaying flesh, fungi, fruits, and even dead millipedes and ants! Like all beetles, dung beetles have two sets of wings: a flexible interior pair used for flight, and a tough exterior pair that serves as armor. All dung beetles have antennae that widen at the ends into a club, and the males of some species have impressive horns that they use when fighting for females (Figure 1C). There are more than 7,000 different species of dung beetles, and new species are discovered each year.

Dung beetles can be classified into three main groups based on their feeding and nesting habits (Figure 2). The first group are the dweller dung beetles. Dwellers arrive at a pile of dung and quickly take up residence. Inside the dung, they mate and lay eggs. Once hatched, the larvae (the immature form of the beetles) spend the entirety of their development feeding within the pile of dung that serves as a home and a food source (Figure 2A). The second group are the tunnellers. Female tunneller beetles arrive at the dung and begin digging a tunnel in the soil. They drag small pieces of dung into the tunnel, forming the pieces into lumps called brood balls. The males then compete for a female and her tunnel, which they defend until the female is mated and lays her eggs in the dung (Figure 2B). Then there are the rollers. A male arrives at the dung and sculpts it into a ball using his hind legs. If the dung ball is to the female's liking, he rolls it away and begins burying the dung in the soil. Once buried, the female lays an egg inside the ball and the larva feeds on the dung ball for the entirety of its development-safe and sound in the soil (Figure 2C). Whichever method a dung beetle uses for feeding and nesting, its activities add and mix organic matter into the soil. This is extremely important for other soil animals and microbes and provides a boost of nutrients to plant roots. 
Figure 2

Three different nesting strategies used by dung beetles. (A) Dweller beetles lay eggs directly into the dung where the larvae spend the entirety of their development. (B) Tunneller beetles dig tunnels in the soil where they form small balls of dung known as brood balls. The female lays eggs into those brood balls, where the larvae will feed. (C) Roller dung beetles sculpt a ball of dung and roll it away to safety, before burying it into the soil and laying eggs.

\section{BIODIVERSITY}

The variety of life on Earth.

\section{FRAGMENTATION}

The process of being split into smaller patches.

\section{RESILIENT}

Able to withstand changes in the environment

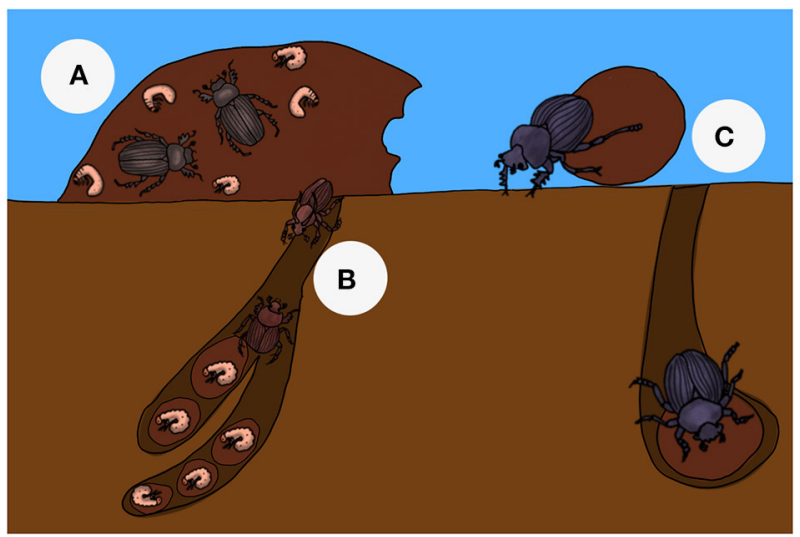

Figure 2

\section{DUNG BEETLES IN TROPICAL FOREST ECOSYSTEMS}

Dung beetles form networks of interactions with the mammals whose dung they feed on. Both mammals and dung beetles have interactions with the fruiting plants whose seeds they disperse in the dung (Figure 3A). However, if some mammals become extinct, this may affect the dung beetles that feed on their dung and the distribution of the plants whose seeds they help disperse [1] (Figure 3B). We have been studying the interactions among mammals and dung beetles in the tropical forests of Brazil, Singapore, and Malaysia. These tropical forests have lost biodiversity because of deforestation, fragmentation, and hunting. We expect that as the forests become more disturbed and fragmented into smaller patches, the number of mammal species would decline, and we would also see fewer dung beetles. We predict that the complex interactions between mammals, dung beetles, and fruiting plants would be simpler in disturbed areas and isolated forest patches compared to large and healthy tropical forest.

To test our prediction, we set up traps baited with dung from different mammals in habitats ranging from forests to oil palm plantations. We looked at large areas of continuous forest and small forest patches. We then counted and identified the beetles that were attracted to each dung type in each habitat. We found that tropical forest dung beetle-mammal networks are fairly resilient, meaning they do not change very much in response to logging and fragmentation. We think this is because dung beetles are not very fussy about what kind of dung they eat. While many beetles have a preferred food type, few specialize only on a single dung type. So, if one mammal species is lost from an area, most dung beetles can simply switch to the dung of another mammal species for their next meal (Figure 3B). We discovered that some dung beetles even feed on python dung! However, although networks were resilient in moderately disturbed habitats, we found that in heavily disturbed sites, such as oil palm plantations and small isolated forest patches, the networks did become simplified, with 
Figure 3

Simplified interactions among mammals, dung beetles, and seeds in (A) an undisturbed ecosystem, (B) a moderately disturbed or fragmented ecosystem, and (C) a heavily disturbed or fragmented ecosystem The loss of species and interactions are shown in gray. Three types of interactions are possible: (1) mammal-seed-only the mammals disperse the seeds; (2) mammal-dung beetle-there is no seed dispersal; (3) mammal-dung beetle-seed-both mammals and dung beetles disperse seeds. In moderately disturbed or fragmented ecosystem (B), dung beetles can switch their feeding preferences to a different dung. This does not happen in heavily disturbed or fragmented ecosystem (C), so the beetle and its interactions are lost.

\section{ECOSYSTEM}

A community of animals, plants, bacteria, and fungi living in a particular location along with the non-living components of that environment.

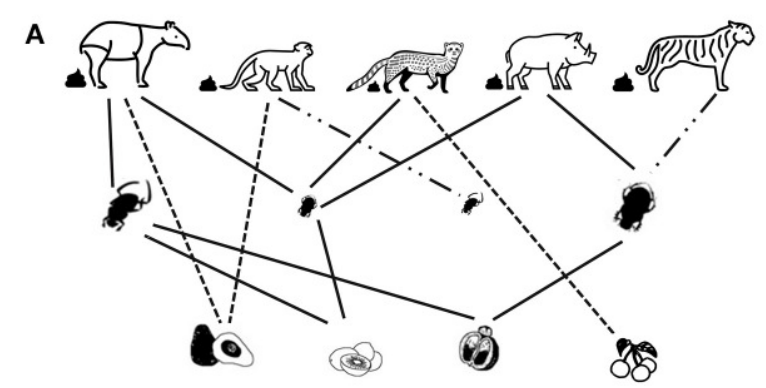

B

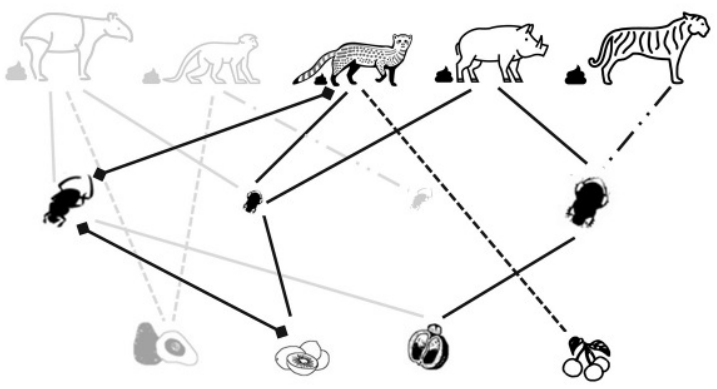

C

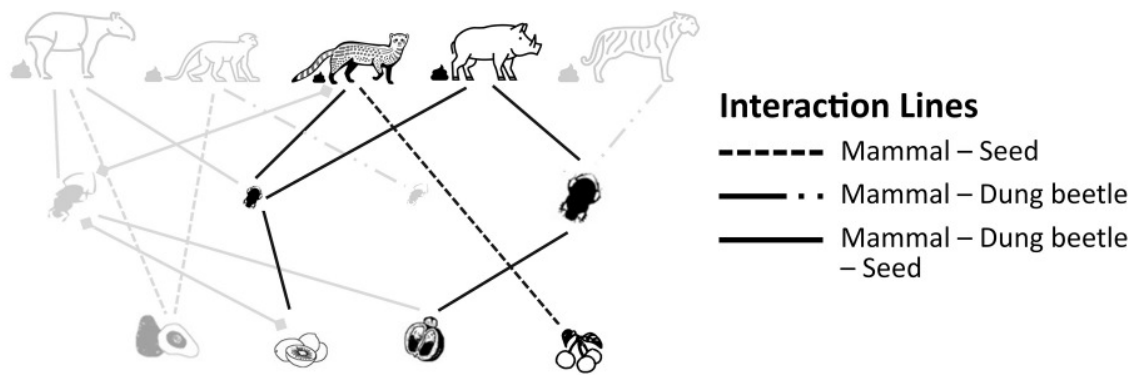

Figure 3

fewer dung beetle species and fewer interactions between beetles and mammals [2] (Figure 3C).

Using traps baited with dung to catch beetles only tells us if the beetles are attracted to the dung, but not if those beetles actually feed on that dung type. We could only bait traps with dung from mammals that we could easily find, like animals kept in zoos. Luckily, new laboratory methods are allowing us to know exactly which mammal dung the beetles have been feeding on. So, in our current work, we are dissecting the guts of beetles to analyze the genetic material of the beetle gut contents. This method allows us to identify which mammal dung the beetles were feeding on before they were captured. We hope that this will allow us to document more complete networks, including rare or difficult-to-study mammal species, and the interactions between mammals and dung beetles that live in the forest canopy-yes, there are canopy dung beetles too!

\section{DUNG BEETLES IN AGRICULTURAL ECOSYSTEMS}

Dung beetles are important members of agricultural ecosystems, and many researchers have explored how dung beetles help support the 


\section{NEMATODES}

A group of worms, also known as roundworms found in soil and aquatic environments that can be parasites in plants and animals.

\section{PARASITICIDES}

Drugs given to animals to kill their parasites. production of food [3]. For example, flies that bite and disturb cows and other farm animals, lay their eggs in dung and the immature fly larvae then feed on dung when they hatch. Dung beetles help to keep farm animals like sheep, cows, and horses healthier by burying farm animal dung, so that it is not available for the flies to breed in.

Dung beetles also help to reduce parasite infections of farm animals. Parasitic nematodes, which are tiny worms, are eaten by animals grazing in the pastures. The nematodes then multiply in the animals and their eggs are excreted in the dung. When the eggs hatch, the larvae migrate to the grass and are ingested by grazing animals, like cows or sheep, which quickly increases the infection rates. When dung beetles tunnel through dung, they cause it to dry out. This kills the eggs, and reduces the numbers of parasitic nematodes in the pasture, which leads to fewer infected animals. This tunneling action also helps with the recycling and mixing of the soil, which aids the movement of nutrients through the soil so they can be available by plants. Because dung beetles are relatively small and often secretive, many farmers may not even recognize that dung beetles live on their farms. However, despite their small size, dung beetles save the cattle industry in the United Kingdom alone about $£ 367$ million per year [4]!

Dung beetles are sensitive to how pastures are managed. In one study, scientists collected beetles from a series of cattle farms in Ireland [5]. They compared conventional farms that used artificial fertilizers and insecticides to organically managed farms, which used neither. The researchers found that organic farms had a greater abundance of dung beetles and more dung beetle species than the other type of farms. We then discovered that having more dung beetle species increases plant growth, but has no benefit for improving the number of air pockets in the soil [6].

Parasiticides are also a serious threat to dung beetles living in agricultural ecosystems. These are chemicals given to farm animals to protect them against parasites, such as ticks, fleas, and nematodes. Parasites harm the animals by feeding on their blood and sometimes transmitting diseases. Parasiticides are generally excreted in animal dung, so the same chemicals that kill the parasites can also affect dung beetles when they then feed on the dung. Sadly, we discovered that a parasiticide commonly used to treat farm animals can kill dung beetles or stop them from breeding. This reduces the health and number of dung beetles and the amount of dung they bury [6]. Farmers can help protect their dung beetles by using fewer parasiticides, by treating only those animals with high numbers of parasites, or choosing treatments that are less toxic to dung beetles. 


\section{THE PRECIOUS AND FASCINATING DUNG BEETLE}

As you can see, dung beetles are precious. As you now know, they have many important ecological roles in natural and agricultural ecosystems, and can help us understand more about the health of ecosystems. For example, because dung beetles are linked to mammals, if we notice that some dung beetle species disappear from our forests, this suggests that the forest mammals might be disappearing too. Healthy soils and plants need nutrients, which dung beetles and other soil animals help provide. The disappearance of dung beetles and other soil animals due to chemical and environmental disturbances would lead to our soils becoming infertile, and the seeds of many plants would not be dispersed or grow. The many different behaviors that dung beetles exhibit have put them in the spotlight of numerous fascinating behavioral studies. Findings have included beetles navigating using the milky way, and others dispersing the seeds of a plant that have tricked the beetle by evolving to look and smell like antelope dung! Keep an eye open for these fascinating creatures wherever you find yourself, you never know what discoveries you might make.

\section{ACKNOWLEDGMENTS}

We were grateful to Chien C. Lee for allowing us to use his photos of dung beetles taken in Sabah, Malaysia-his photography can be found at www.chienclee.com.

\section{REFERENCES}

1. Raine, E. H., and Slade, E. M. 2019. Dung beetle-mammal associations: methods, research trends and future directions. Proc. R. Soc. $B$ 286:20182002. doi: 10.1098/rspb.2018.2002

2. Ong, X. R., Slade, E. M., and Lim, M. L. M. 2020. Dung beetle-megafauna trophic networks in Singapore's fragmented forests. Biotropica 52:818-24. doi: 10.1111/btp.12840

3. Nichols, E., Spector, S., Louzada, J., Larsen, T., Amezquita, S., Favila, M., et al. 2008. Ecological functions and ecosystem services of Scarabaeinae dung beetles. Biol. Conserv. 141:1461-74. doi: 10.1016/j.biocon.2008.04.011

4. Beynon, S. A., Wainwright, W. A., and Christie, M. 2015. The application of an ecosystem services framework to estimate the economic value of dung beetles to the UK cattle industry. Ecol. Entomol. 40:124-35. doi: 10.1111/een.12240

5. Hutton, S. A., and Giller, P. S. 2003. The effects of the intensification of agriculture on northern temperate dung beetle communities. J. Appl. Ecol. 40:994-1007. doi: 10.1111/j.1365-2664.2003.00863.x

6. Manning, P., Slade, E. M., Beynon, S. A., and Lewis, O. T. 2017. Effect of dung beetle species richness and chemical perturbation on multiple ecosystem functions. Ecol. Entomol. 42:577-86. doi: 10.1111/een.12421 
SUBMITTED: 15 July 2020; ACCEPTED: 25 March 2021;

PUBLISHED ONLINE: 22 April 2021.

EDITED BY: Helen Phillips, German Centre for Integrative Biodiversity Research (iDiv), Germany

CITATION: Manning P, Ong XR and Slade EM (2021) Dung Beetles Help Keep Ecosystems Healthy. Front. Young Minds 9:583675. doi: 10.3389/frym.2021.583675

CONFLICT OF INTEREST: The authors declare that the research was conducted in the absence of any commercial or financial relationships that could be construed as a potential conflict of interest.

COPYRIGHT @ 2021 Manning, Ong and Slade. This is an open-access article distributed under the terms of the Creative Commons Attribution License (CC BY). The use, distribution or reproduction in other forums is permitted, provided the original author(s) and the copyright owner(s) are credited and that the original publication in this journal is cited, in accordance with accepted academic practice. No use, distribution or reproduction is permitted which does not comply with these terms.

\section{YOUNG REVIEWERS}

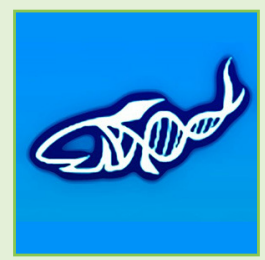

\section{FDR-HB_PERU IGEM TEAM, AGES: 14-17}

We are a synthetic biology team with the international Genetically Engineered Machine (iGEM) in Lima, Peru. We are the only high school team in Latin America and are proud of our work with creating a detector for cadmium using bacteria. Most of us are second language learners and the age range of our group is 14-17 years old. We love GMOs!

\section{AUTHORS}
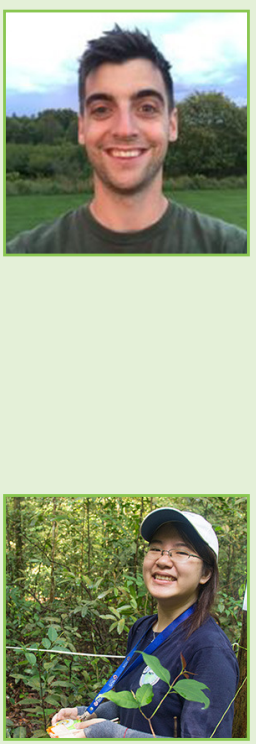

\section{PAUL MANNING}

Paul is a post-doctoral fellow at the Faculty of Agriculture at Dalhousie University. He holds a B.Sc. in agriculture from the Nova Scotia Agricultural College, and a D.Phil. in Zoology from the University of Oxford. He has been working on dung beetle ecology and toxicology since 2013. His research aims to understand how insect communities support ecosystem functions (like dung decomposition) in agricultural ecosystems. Paul is also interested in elevating public understanding and appreciation of insects through speaking to community groups, working with youth, and conducting research through participatory citizen science. *paul.manning@dal.ca

\section{XIN RUI ONG}

Xin Rui is a Ph.D. student at the Asian School of the Environment in Nanyang Technological University. She graduated from the National University of Singapore with a B.Sc. in Life Sciences, specializing in Environmental Biology. Xin Rui was first introduced to the fascinating world of dung beetles during her undergraduate years 
and is now studying the diversity of dung beetles and their interactions with mammal communities in Southeast Asia.

\section{ELEANOR M. SLADE}

Eleanor is an Assistant Professor at the Asian School of the Environment. She holds a B.Sc. in Zoology from the University of Leeds, a M.Sc. in Ecology from Aberdeen University, and a D.Phil. in Zoology from the University of Oxford. Eleanor is an ecologist whose research focuses on the conservation, management, and restoration of tropical forest landscapes and agricultural systems. She is particularly interested in invertebrates and has been studying dung beetles and their importance for healthy ecosystems for 17 years. Eleanor is also interested in using science to help inform policy and best practices in the oil palm industry. 